\title{
A study of corrosion of zinc-coated stranded steel wire used as messenger wire
}

\author{
T. Kuraoka \& Y. Sato \\ Railway Technical Research Institute, Japan
}

\begin{abstract}
Zinc-coated stranded steel wires are widely used for messenger wires of the overhead catenary system. Though these wires have been uniformly replaced mainly based on aging, the corrosion speed of the wire, which is the main factor of the degradation, is thoroughly different depending on the installed environment. The purpose of this study is to propose a replacement period of zinc-coated stranded steel wire according to the installed environment. In order to investigate the corrosive situation of the messenger wire under the current environmental conditions, we carried out the measurement of the residual amount of zinc and iron of the wire installed under various environments by using a deterioration detection device as developed by our laboratory, and examined the relation between corrosion and aging. Consequently, the estimated period for the zinc plating elimination was twenty years in seashore areas, thirty years in city areas, and fifty years in mountainous areas respectively as the lower estimate. On the other hand, there was almost no reduction in iron remains in every environment because of the anticorrosive effect of zinc on iron. Moreover, we carried out a tensile test and a vibration test in order to evaluate the relation between corrosion and the mechanical characteristics of zinc-coated stranded steel wires for which corrosion was accelerated by using the salt spray test system. As a result, the vibration fatigue characteristic of the wires greatly deteriorated when iron corroded. From these results, it was evident that the limit of service life of messenger wires should be set at the time point when the zinc plating disappeared. Furthermore, we confirmed that the ACM (Atmosphere Corrosion Monitoring) sensor was useful as a method to estimate the corrosion rate of zinc plating in each environment in a short period.
\end{abstract}

Keywords: corrosion, zinc-coated stranded steel wire, messenger wire, salt spray test, atmosphere corrosion monitoring sensor. 


\section{Introduction}

Zinc-coated stranded steel wires are widely used for messenger wires of the overhead catenary system. These wires have been uniformly replaced mainly based on aging. Generally, in the case of SHINKANSEN lines, the replacement period is set at between twenty to thirty years. However, the corrosion speed of the wire, which is the main factor of the degradation, is thoroughly different depending on the installed environment. Therefore, for the proper maintenance of wires, the replacement period should be changed according to the environment. The purpose of this study is to propose a replacement period of zinc-coated stranded steel wire according to the installed environment.

\section{Investigation of the corrosive situation}

\subsection{Measurement of the residual amount of zinc and iron}

\subsubsection{Measurement for the installed wires}

We carried out the measurement of the residual amount of zinc and iron for the wires installed in various environments by using a deterioration detecting device. This device detects change of eddy current which decreases with degradation of the wire [1]. Figure 1 show an example of the residual amount of zinc and iron, which was measured throughout one tension length of the overhead contact line system. This wire was installed in the mountainous area and was twenty-six years of age. The residual amount of zinc in the tunnel section was more than that in the open section, except for the residual amount at the point of wire on which leakage water was directly dropping in the tunnel section. On the other hand, there was almost no decrease in the residual amount of iron throughout between the overlaps. The same tendency was seen in all measured wires that were aged between eighteen to thirty years, and installed in city areas, mountainous areas, or seashore areas.

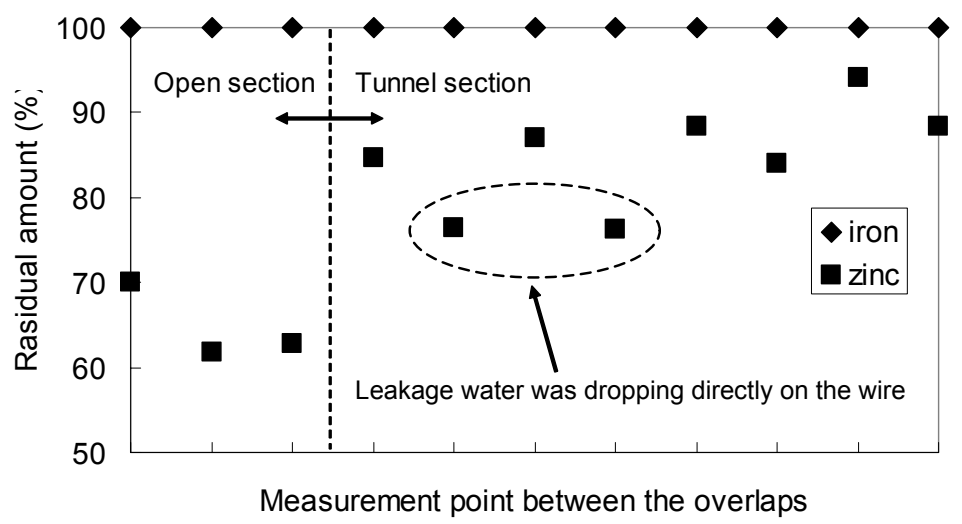

Figure 1: Residual amount of zinc and iron of the wires in service. 


\subsubsection{Measurement for the removed wires}

We carried out the same measurement for the removed wires, which were about thirty years of age. Only the residual amount of zinc was measured, since it was confirmed that the iron was not corroded as described in section 2.1.1. The installed environments are shown in table 1 and the results are shown in fig. 2. Similarly to the result shown in fig. 1, the residual amount of zinc in the tunnel section was more than that in the open section. In the open section of city and seashore areas, the residual amount of zinc of the wire at the midpoint of the supporting points was less than that of the wire near the supporting point. It is considered that this is because the water is apt to flow into the midpoint of the supporting points. In the tunnel section, the difference of the residual amount of zinc could not be observed between the wire at the midpoint of the supporting points and that near the supporting point.

Table 1: $\quad$ Test specimens.

\begin{tabular}{|c|l|l|l|c|}
\hline No. & Installed area & Open / Tunnel & Measured point of wire & Aging \\
\hline 1 & City (Bridge) & Open & Midpoint & 33 \\
\hline 2 & City (Bridge) & Open & Supporting point & 33 \\
\hline 3 & City (Station) & Open & Midpoint & 30 \\
\hline 4 & City (Station) & Open & Supporting point & 30 \\
\hline 5 & Seashore & Open & Midpoint & 30 \\
\hline 6 & Seashore & Open & Supporting point & 30 \\
\hline 7 & Mountainous & Tunnel & Midpoint & 30 \\
\hline 8 & Mountainous & Tunnel & Supporting point & 30 \\
\hline 9 & City & Tunnel & Midpoint & 33 \\
\hline 10 & City & Tunnel & Supporting point & 33 \\
\hline 11 & Seashore & Tunnel & Midpoint & 30 \\
\hline 12 & Seashore & Tunnel & Supporting point & 30 \\
\hline
\end{tabular}

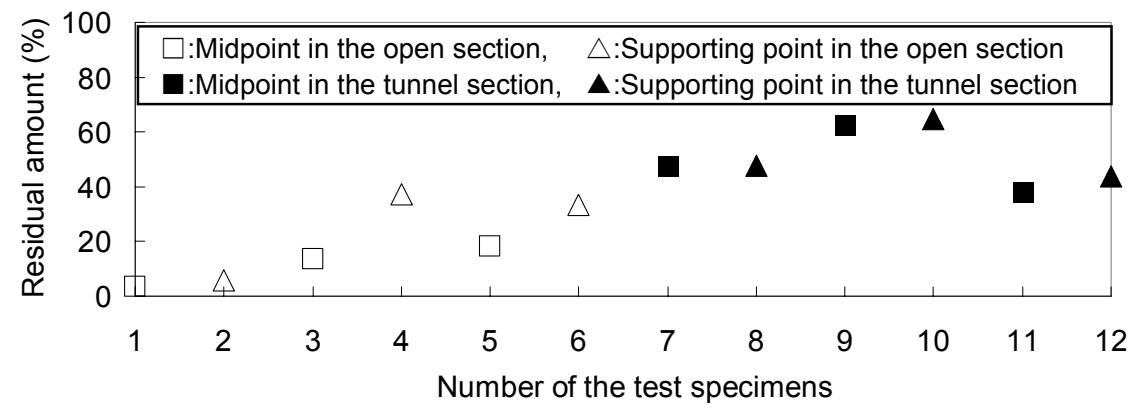

Figure 2: Residual amount of zinc of the removed wires.

\subsection{Relation between diminished zinc and years of installation}

The relation between amount of diminished zinc measured as explained above and years of installation is shown in fig. 3. It indicates that the diminishing rate of zinc in mountainous areas was lower than that in city areas and seashore areas. 
In comparison with the literature value of the diminishing rate of zinc of zinccoated steel plate [2], the measured values in mountainous areas were almost the same, and the measured values in the seashore areas were lower than the literature value. It could be also confirmed that the corrosion speed in the tunnel section was slower than that in the open section.

The shortest estimated period for the zinc plating elimination, which was measured in the city area, was thirty-five years from the results as shown in fig. 3 . Therefore, we consider that the guidepost of the elimination period of zinc plating should be set at thirty years with a margin in the city area. In the seashore area, though the elimination period estimated from the measured value was longer than that in the city area, the elimination period could be estimated to be twenty-three years from the literature value. For the more safety guidepost, we consider that it should be set to twenty years in the seashore area. In the mountainous areas, the shortest estimated period was sixty years. Thus we consider that the guidepost should be set at fifty years.

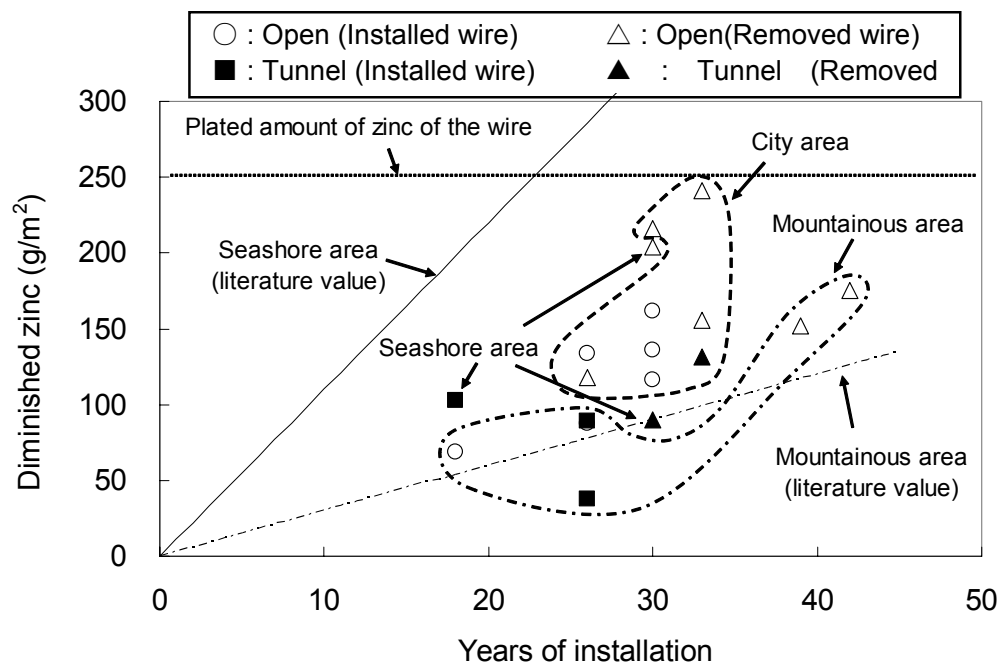

Figure 3: Relation between amount of diminished zinc and years of installation.

\section{Evaluation of the strength degradation as the wire corroded}

In order to evaluate the strength degradation as the wire corroded, we carried out a tensile strength test and a vibration fatigue test on zinc-coated stranded steel wire for which corrosion was accelerated.

\subsection{Accelerated corrosion test}

Accelerated corrosion test was carried out based on ISO/DIS 14993. Table 2 shows the condition of the test. In order to investigate a diminishing rate of both 
zinc and iron, we prepared two types of test specimens. One was a new wire, and another was the wire in which zinc plating was removed beforehand so that iron may efficiently corrode.

Figure 4 shows the relation between number of test cycles and the residual amount of zinc of new wire. The residual amount of zinc decreased at a fixed rate with test cycles. It seems that zinc decreased efficiently due to the sacrifice anticorrosive action of zinc for iron. It is estimated that zinc disappears in 900 cycles, when it decreases at this rate. Figure 5 shows the relation between the number of test cycles and the residual amount of iron of zinc plating removed wire. The diminishing rate of iron became low with increasing test cycles. This is because the rust on the surface of the wire suppressed the iron corrosion.

Table 2: $\quad$ Condition of acceleration corrosion test.

\begin{tabular}{|c|c|l|c|c|c|}
\hline \multirow{2}{*}{} & \multirow{2}{*}{ Steps } & \multicolumn{3}{|c|}{ Environmental condition } & Time \\
\cline { 3 - 6 } & & Situation & Temperature $\left({ }^{\circ} \mathrm{C}\right)$ & Humidity $(\%)$ & $(\mathrm{h})$ \\
\hline \multirow{3}{*}{1 cycle } & 1 & Spray $(5 \% \mathrm{NaCl})$ & 35 & - & 2 \\
\cline { 2 - 6 } & 2 & Dry & 50 & 20 & 2 \\
\cline { 2 - 6 } & 3 & Wet & 50 & 98 & 4 \\
\hline
\end{tabular}

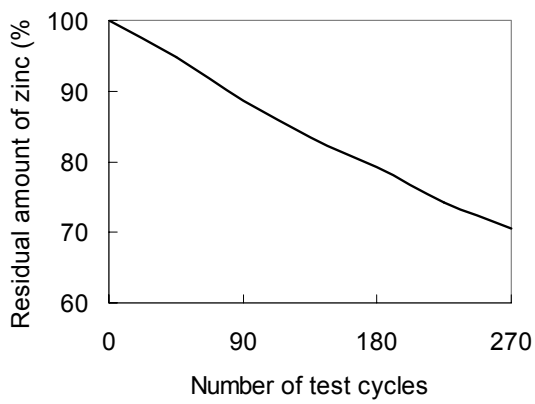

Figure 4: Residual amount of zinc. Figure 5: Residual amount of iron.

\subsection{Tensile strength test}

We carried out a tensile strength test of the test specimen in which iron was corroded as described above. The relation between the number of test cycles and tensile breaking load is shown in fig. 6. Similarly to the diminishing rate of iron shown in fig. 5 , the reduction rate of tensile breaking load became slow with increasing test cycles. When 270 cycles of acceleration corrosion test was finished, the residual amount of iron was about $85 \%$ and tensile breaking load was about $175 \mathrm{kN}$. Therefore, considering that standard tension of this wire is $113 \mathrm{kN}$ and operating tension is $24.5 \mathrm{kN}$, it seems that this wire does not break immediately with the iron corrosion. 


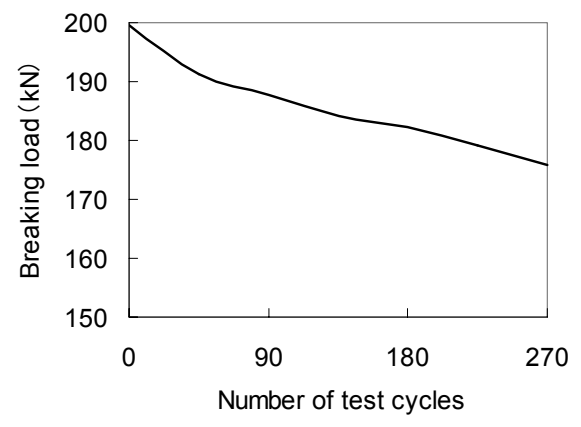

Figure 6: Result of tensile strength test.

\subsection{Vibration fatigue test}

Since the messenger wire vibrates by passage of the pantograph and effect of the wind, it is also necessary to evaluate vibration fatigue characteristic. Test condition was determined in such a way that the applied stress on the wire became the same as that in high speed running of SHINKANSEN. Figure 7 shows a view of vibration fatigue test system, and table 3 shows the test condition of vibration fatigue test.

Figure 8 shows the relation between the residual amount of iron and the number of vibration when one or more wires are broken. The wire breaking was not caused even in the vibration over 10 million times for the new wire, while it was caused in the vibration about of 1.3 million times for the wire in which the iron was corroded.

From these results, it was found out that though the tensile strength of the wire did not deteriorate immediately with the iron corrosion, the vibration fatigue characteristic of the wire greatly deteriorated. Therefore, the use limit of messenger wire should be set at the time point when the zinc plating disappears.

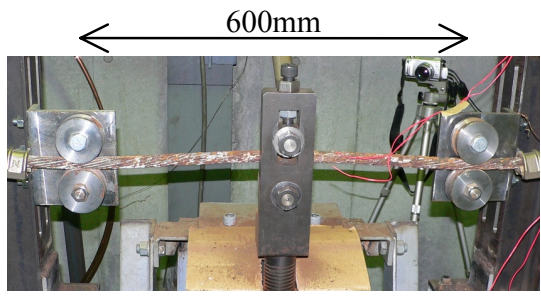

Figure 7: Vibration fatigue test system.

Table 3: $\quad$ Test condition.

\begin{tabular}{|l|c|}
\hline Amplitude (peak to peak) & $20 \mathrm{~mm}$ \\
\hline Frequency & $5 \mathrm{~Hz}$ \\
\hline Tension & $4.9 \mathrm{kN}$ \\
\hline
\end{tabular}




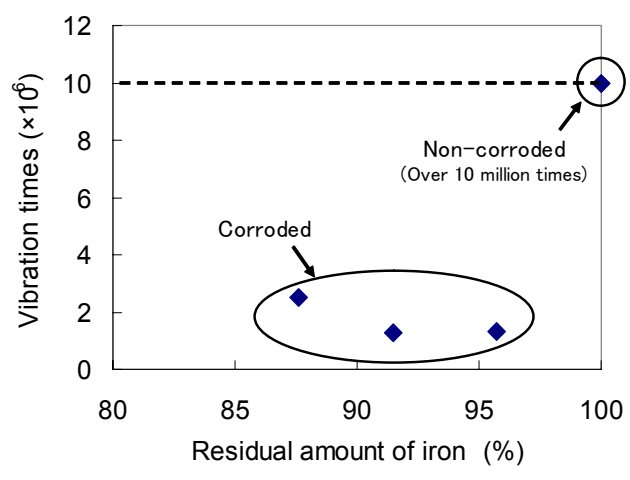

Figure 8: Result of vibration fatigue test.

\section{Estimation of the corrosion rate of zinc plating using $\mathrm{ACM}$ sensor}

\subsection{The composition of the ACM sensor}

Figure 9 shows the composition of the ACM sensor. Carbon steel plate, $64 \mathrm{~mm}$ square, and $0.8 \mathrm{~mm}$ thick, is used for the base metal substrate, and $\mathrm{Ag}$ based conductive paste is used for the noble metal. In order to insulate both metals, insulation paste made of the epoxy resin containing BN (boron nitride) is applied between carbon steel plate and Ag paste. As shown in fig. 9, the sensor has the slit shape part on which these pastes are not applied, so that carbon steel plate is exposed at this part. Carbon steel plate corrodes when the sea salt particles $(\mathrm{NaCl}, \mathrm{MgCl} 2$, etc.) or the atmosphere components (SO2, etc.) adhere directly or in the condition of the aqueous solution.

As thin water film is formed by rain water or dew condensation, the electron dissolves out into water film from $\mathrm{Fe}$ of the carbon steel plate. On the carbon steel plate, the reaction occurs as follows:

$$
2 \mathrm{Fe} \rightarrow 2 \mathrm{Fe} 2++4 \mathrm{e}-\text {. }
$$

On the Ag paste, the reaction occurs as follows:

$$
\mathrm{O} 2+2 \mathrm{H} 2 \mathrm{O}+4 \mathrm{e}-\rightarrow 4 \mathrm{OH}-\text {. }
$$

The electron transferred by these reactions flows in the lead wire, which connects carbon steel plate with Ag paste. Therefore, by measuring this current, it is possible to estimate the corrosive situation in exposed environment.

\subsection{The output of the ACM sensor}

If the output characteristic of the ACM sensor in the acceleration corrosion test is grasped, it can be possible to estimate the relation between the output of the ACM sensor in the actual environment and the number of cycles of the accelerated corrosion test. In addition, the elimination period for the zinc plating in the actual environment can be also estimated, since we have estimated that the zinc plating disappears in 900 cycles of the accelerated corrosion test. 
Figure 10 shows the output characteristic of the ACM sensor exposed in the accelerated corrosion system. The current flowed during wet and salt spraying periods, but did not flow during a dry period. The relation between the integrated current and the number of test cycles is shown in fig. 11. The integrated current $\mathrm{Q}(\mathrm{Ah})$ can be approximated as follows by using the number of test cycles $\mathrm{N}$ :

$$
Q=0.0246 \ln (N)+0.0063 \text {. }
$$

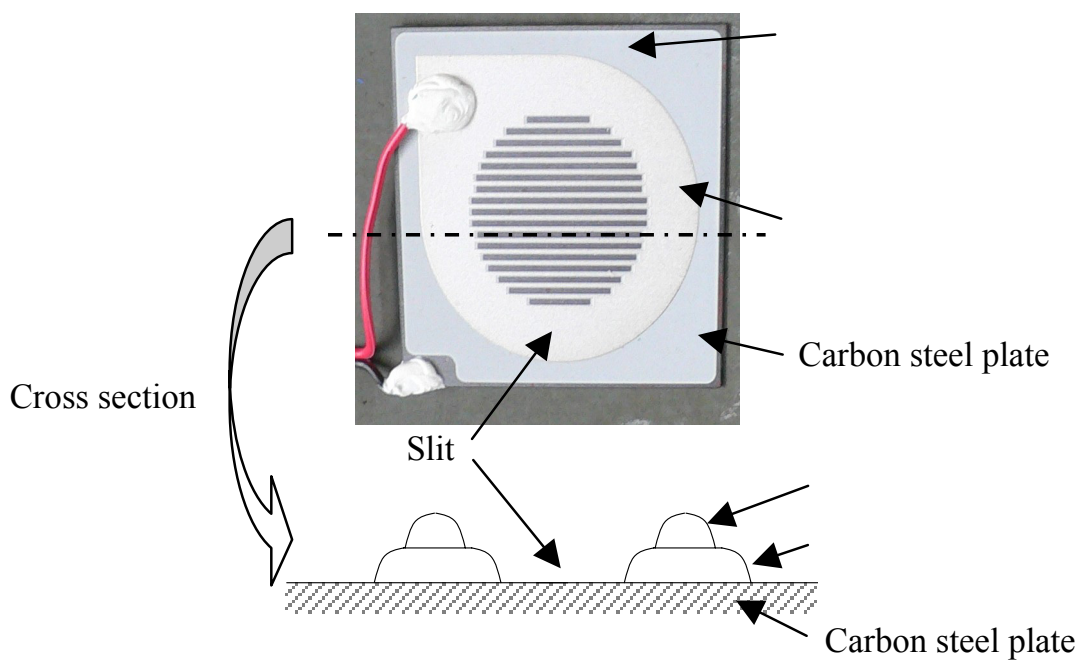

Figure 9: Composition of the ACM sensor.

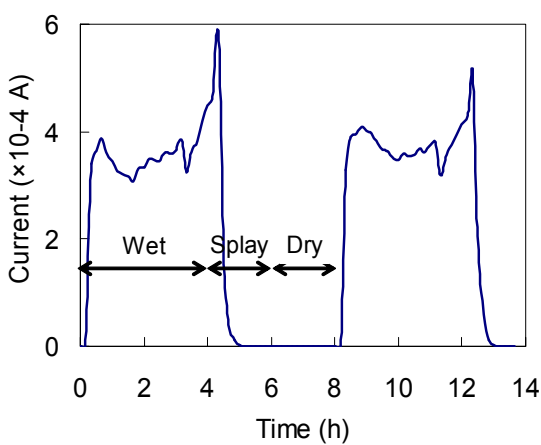

Figure 10: Output characteristic of the ACM sensor.

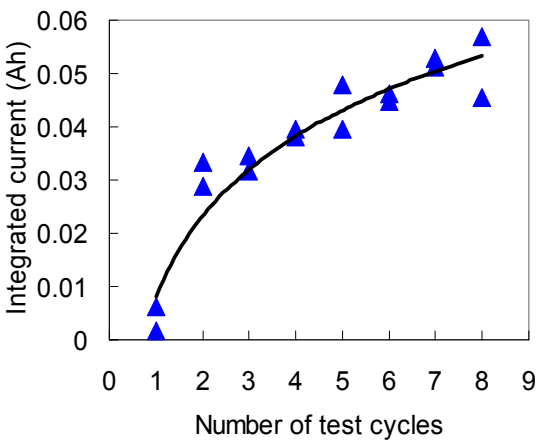

Figure 11: Relation between integrated current and test cycles. 


\subsection{Estimation of the elimination period of the zinc plating using the ACM sensor}

We measured the integrated current in several environments to estimate the elimination period of the zinc plating in each environment. The measurement periods were from about one month to three months. When the measured integrated current $\mathrm{Q}$ is substituted into the eqn. (3), the number of test cycles $\mathrm{N}$ that corresponds to the installed days of the ACM sensor in each environment can be calculated. The installed days divided by $\mathrm{N}$ represent the days in each environment equivalent to one cycle of accelerated corrosion test. Then we obtain the estimated elimination period for the zinc plating in each environment, since we have estimated that the zinc plating disappears in 900 cycles of accelerated corrosion test.

Table 4 shows the elimination period estimated by this method. In order to verify the accuracy of this method, we carried out the measurement of the residual amount of zinc in the cases of No.2 and 3, and estimated the elimination period of the zinc plating from the relation between the residual amount and the aging as also shown in Table 4. As a result, we have obtained that the error of the elimination period estimated by both method is about $20 \%$.

From these results, we confirmed that the ACM sensor was useful to evaluate the corrosion situation easily in a short period. In order to raise the accuracy of this method, we consider that it is necessary to accumulate more data.

Table 4: Estimated elimination period of the zinc plating using the ACM sensor.

\begin{tabular}{|c|l|c|c|c|c|}
\hline \multirow{2}{*}{ No. } & \multirow{2}{*}{ Installed area } & $\begin{array}{c}\text { Integrated } \\
\text { current (Ah) }\end{array}$ & \multirow{2}{*}{$\begin{array}{c}\text { Installed } \\
\text { period (day) }\end{array}$} & \multicolumn{2}{|c|}{ Estimated elimination period (year) } \\
\hline 1 & Sheashore area & 0.045 & 31 & 16 & \\
\hline 2 & Industrial area & 0.038 & 93 & 40 & 46 \\
\hline 3 & City area & 0.036 & 60 & 44 & 55 \\
\hline 4 & Residential area & 0.028 & 60 & 62 & Residual amount \\
\hline
\end{tabular}

\section{Conclusion}

In this study, in order to propose a replacement period of zinc-coated stranded steel wire according to the installed environment, we investigated the corrosive situation of the messenger wires installed under various environments, and evaluated the strength degradation of the wire with the corrosion.

As a result, we confirmed that the residual amount of zinc was different in each environment, while there was almost no reduction in iron remains in every environment. The estimated period for the zinc plating elimination was twenty years in seashore areas, thirty years in city areas, and fifty years in mountainous areas respectively as the lower estimate. On the other hand, though the tensile strength of the wire did not deteriorate immediately with the iron corrosion, the vibration fatigue characteristic of the wires greatly deteriorated when iron 
corroded. Therefore, it was evident that the limit of service life of messenger wires should be set at the time point when the zinc plating disappeared.

Furthermore, we confirmed that the ACM sensor was useful as a method to estimate the corrosion rate of zinc plating in each environment in a short period.

\section{References}

[1] Shimada, T., Satoh, Y. \& Kohida, T., Development of Device for Detecting Deterioration of Galvanized Steel Stranded Wires. RTRI REPORT, Vol.12, No.7, pp.25-30, 1998 (in Japanese)

[2] Japanese Standards Association, Hot dip galvanized coatings, JIS H8641, 2007 